\title{
Disentangling the Influence of Urbanization and Invasion on Endemic Geckos in Tropical Biodiversity Hot Spots: A Case Study of Phyllodactylus martini (Squamata: Phyllodactylidae) along an Urban Gradient in Curaçao
}

\author{
Alex Dornburg' ${ }^{1}$, Cat Lippi², Sarah Federman³ ${ }^{3}$ Jon A. Moore ${ }^{4,5}$, Dan L. Warren ${ }^{6}$, Teresa L. Iglesias ${ }^{6}$, \\ Matthew C. Brandley ${ }^{7}$, Gregory J. Watkins-Colwell ${ }^{8}$, April D. Lamb ${ }^{9,10}$ and Andrew Jones ${ }^{11}$ \\ ${ }^{1}$ Corresponding author: North Carolina Museum of Natural Sciences, Raleigh, NC 27601 USA \\ _email: alex.dornburg@naturalsciences.org \\ ${ }^{2}$ Emerging Pathogens Institute, University of Florida, Gainesville, FL 32610 USA \\ ${ }^{3}$ Department of Ecology and Evolutionary Biology, Yale University, New Haven, CT 06520 USA \\ ${ }^{4}$ Florida Atlantic University, Wilkes Honors College, Jupiter, FL 33458 USA \\ ${ }^{5}$ Florida Atlantic University, Harbor Branch Oceanographic Institution, Fort Pierce, FL 34946 USA \\ ${ }^{6}$ Department of Biological Sciences, Macquarie University, North Ryde, New South Wales 2109 Australia \\ ${ }^{7}$ School of Biological Sciences, University of Sydney, New South Wales 2006 Australia \\ ${ }^{8}$ Division of Vertebrate Zoology, Yale Peabody Museum of Natural History, New Haven, CT 06520 USA \\ ${ }^{9}$ Department of Biological Sciences, North Carolina State University, Raleigh, NC 27695 USA \\ ${ }^{10}$ North Carolina Museum of Natural Sciences, Raleigh, NC 27601 USA \\ ${ }^{11}$ Department of Biology, Woods Hole Oceanographic Institution, Woods Hole, MA 02543 USA
}

\begin{abstract}
Predicting the response of endemic species to urbanization has emerged as a fundamental challenge in 21 st century conservation biology. The factors that underlie population declines of reptiles are particularly nebulous, as these are often the least understood class of vertebrates in a given community. In this study, we assess correlations between feeding ecology and phenotypic traits of the Lesser Antillean endemic Dutch leaf-toed gecko, Phyllodactylus martini, along an urban gradient in the Caribbean island of Curaçao. There has been a marked decline of this species in developed habitats associated with the invasive tropical house gecko Hemidactylus mabouia. We find a correlation between aspects of locomotor morphology and prey in undeveloped habitats that is absent in developed habitats. Analyses of stomach contents further suggest that Phyllodactylus martini alters primary prey items in developed areas. However, changes in prey promote the overlap in foraging niches between Phyllodactylus martini and Hemidactylus mabouia, suggesting that direct resource competition is contributing to the decline of Phyllodactylus martini. In addition to competitive exclusion, we suggest that the urban extirpation of Phyllodactylus martini could also be attributed to a top-down control on population growth by Hemidactylus mabouia. Colonizations of walls put Phyllodactylus martini in direct contact with Hemidactylus mabouia increasing the chances for predation events, as evidenced by our observation of a predation event on a Phyllodactylus martini juvenile by an adult Hemidactylus mabuoia. In total, our results add to a growing body of literature demonstrating the threat that invasive synanthropic reptiles pose to endemics that might otherwise be able to cope with increased urbanization pressures.
\end{abstract}

\section{KEYWORDS}

Urbanization, Caribbean biodiversity hot spot, conservation, invasive species, Hemidactylus mabouia, predation, Anthropocene, extinction, functional morphology, sexual dimorphism 


\section{Introduction}

Understanding the effect of anthropogenic change on native species is a topic of considerable priority for long-term conservation efforts in biodiversity hot spots, which contain at least $44 \%$ of all living plant and $35 \%$ of all living vertebrate taxa, yet only comprise approximately $1.4 \%$ of the planet's total land area (Myers et al. 2000). Tropical hot spots are of particular concern as these regions are experiencing some of the world's highest rates of human population growth (Cincotta et al. 2000) and habitat loss (Myers et al. 2000; Sodhi et al. 2004; Seto et al. 2012). There is substantial evidence documenting population declines of native taxa in these regions, which has led to the hypothesis that tropical species are at disproportionate extinction risk relative to temperate species (Brook et al. 2008). Although this pattern of extinction risk is found across all major vertebrate clades (Gibbons et al. 2000; Brooks et al. 2002; Brook et al. 2008), studies of reptile declines are perhaps the most limited (Gibbons et al. 2000; Garden et al. 2007). In many cases, population declines or local extinctions of reptile species go unnoticed for extended periods of time (Gibbons et al. 2000; Zavaleta et al. 2001; Kraus 2008; Fisher and Ineich 2012). Even when population declines are observed, we often lack the empirical data necessary to assess what factors drive changes in reptile population dynamics (Echternacht 1999; Gibbons et al. 2000).

Over the past several decades, there has been a documented decline in reptile species endemic to the islands of Aruba, Bonaire and Curaçao $(\mathrm{ABC})$. Together these islands represent the most southwestern component of the Caribbean biodiversity hot spot (Myers et al. 2000) with a reptilian fauna that is approximately $50 \%$ endemic (Van Buurt 2005, 2006). These arid islands are considered biogeographically isolated from the Caribbean West Indies, with over-water dispersal from the South American mainland hypothesized as the primary pathway for terrestrial colonization (Koopman 1958, 1959; Staton and Dixon 1977; McFarlane and Lundberg 2002; Debrot 2003; Wüster et al. 2005; Zijlstra et al. 2010; MuñozGaray and Mantilla-Meluk 2012; Rivas et al. 2013). Despite the close geographic distance and taxonomic affinity between the $\mathrm{ABC}$ islands and the mainland, high rates of endemism have led to the hypothesis that these islands comprise a distinct biogeographic province (Van Buurt 2006). However, the long-term persistence of $\mathrm{ABC}$ endemic reptile species is of concern, as they are under increasing pressure from not only human population growth and urban development, but also the spread of invasive reptile species (Van Buurt 2005, 2006).

The continual arrival and establishment of nonnative reptiles has resulted in a $30 \%$ increase in reptile species richness across the $\mathrm{ABC}$ islands (Van Buurt 2005, 2006). Modeling the effect that these new colonizers will have on native species is rendered difficult by gaps in our knowledge of the ecology and natural history of $\mathrm{ABC}$ island endemics and the association of several invasive species with the urban landscape. The endemic Dutch leaf-toed gecko Phyllodactylus martini (Lidth de Jeude 1887) seems particularly vulnerable to urban growth patterns and is notably absent from many portions of its former range (Van Buurt 2005, 2006). Although this toe pad-bearing gecko will readily colonize human dwellings (Van Buurt 2005, 2006), there is a notable decrease of $P$. martini abundance as distance from natural habitats increases (Hughes et al. 2015). Displacement by the nonnative tropical house gecko, Hemidactylus mabouia (Moreau de Jonnès, 1818), is hypothesized to underlie this population decline of $P$. martini (Hughes et al. 2015).

Hemidactylus geckos are often deemed "weedy" species (Kluge 1969; Carranza and Arnold 2006) and have been linked to the displacement of various gecko species through the New World (Meshaka et al. 2006; Reynolds and Niemiller 2010). Disentangling how much of this displacement is because of direct prey resource competition in contrast to other factors is often challenging, as there is little documentation concerning the natural history of Phyllodactylus martini. For example, although $P$. martini will readily colonize walls and other human structures (Van Buurt 2005, 2006; Hughes et al. 2015), it remains unknown whether this habitat shift corresponds with a shift in prey resource availability. Urban development often corresponds with substantial changes in arthropod communities (Gibbs and Stanton 2001; Shochat et al. 2004), and the continual pace of development on the island raises the question of how changes at lower trophic levels 
influence the feeding ecology of $P$. martini. Can $P$. martini shift its diet in response to changes in the prey resource community? If the diet of $P$. martini should change, would it then overlap with that of H. mabouia, which primarily consumes arthropods associated with urban habitats (Iturriaga and Marrero 2013)?

Here we examine the trophic ecology, ecomorphology and dispersal opportunities of Phyllodactylus martini along an urban gradient, with the goal of identifying factors potentially affecting the persistence of this species in the face of anthropogenic pressures and species competition. We provide the first detailed analysis of the diet of P. martini based on specimens collected from around the island of Curaçao and test whether transitions to suburban habitats lead to a shift in dietary resources indicating dietary flexibility. Because many geckos are sexually dimorphic (Kratochvíl and Frynta 2002; Werner and Seifan 2006; Starostová et al. 2010), including other species of Phyllodactylus (Ramírez-Sandoval et al. 2006), we compare feeding habits between sexes to account for the possibility of males and females utilizing different prey resources. We contrast this data with a morphometric data set of limb and cranial elements in P. martini to test for the potential for sexual dimorphism as well as correlations between phenotype and diet. Using spatial analyses, we further test for dispersal abilities between existing natural parks and developed areas sampled in this study to quantify the degree of habitat fragmentation experienced by $P$. martini. Finally, we provide a detailed account of the first observation of the invasive gecko Hemidactylus mabouia preying on $P$. martini.

\section{Materials and Methods}

\section{Data Collection}

Sixty-nine adult Phyllodactylus martini individuals were collected and prepared as research specimens between July 2009 and September 2011 from three locations across northern Curaçao that represent both developed (Westpunt and Lagun) and undeveloped (vicinity of Shete Boca) habitats (Figure 1). Three additional P. martini individuals were collected opportunistically at the Caribbean Research and Management of Biodiversity (CARMABI) research station and used to supplement the morphological data set. The low sample size and distance to the other areas render these samples inadequate for meaningful comparison of dietary differences between sites. Specimens and stomach contents were deposited in the Division of Vertebrate Zoology Herpetology Collection (Reptiles), Peabody Museum of Natural History, Yale University, New Haven, Connecticut, USA (YPM HERR; Appendix 1). Geckos were collected by hand at least 1 hour after complete sunset to increase the probability of stomachs containing freshly ingested prey. To test for differences in ecomorphology between sexes and correlations with ecomorphology and diet, we used calipers to measure a total of 10 morphological traits for each specimen at a precision of 0.01 $\mathrm{mm}$ : (1) snout-vent length (SVL), (2) postorbital width, (3) temporalis width, (4) head length, (5) jaw length, (6) head height, (7) upper forelimb, (8) lower forelimb, (9) upper hind limb and (10) lower hind limb.

\section{Stomach Content Analyses}

For each individual specimen, the stomach was removed and preserved in 10\% formalin for later analysis. All stomach contents were identified and enumerated under a dissecting MVX10 microscope (Olympus Corp.; http://www.olympus-life science.com/). Prey items were identified to the lowest taxonomic grouping possible, with categories largely overlapping with other studies of Caribbean lizards (Perry 1996). Preliminary observations indicated a high frequency of prey item fragments in stomach contents, suggesting that volume or size analyses of individual prey items would not provide representative metrics across the uneven distribution of prey preservation in our specimens (Perry 1996). Thus, we restricted quantification of gut contents to the number of identified prey taxa found in each stomach.

Percent frequency of stomach content items was calculated for each individual within each sampling locality. Differences in gut contents were visualized using nonmetric multidimensional scaling (NMDS) in the vegan software package in R, v. 2.4 (Oksanen et al. 2007; Oksanen 2011) using sex or sampling locality as groups. We quantified stress values to assess whether NMDS ordination is a viable indicator of the dissimilarity between groups, with stress values less than 0.1 indicating good representation of the dissimilari- 

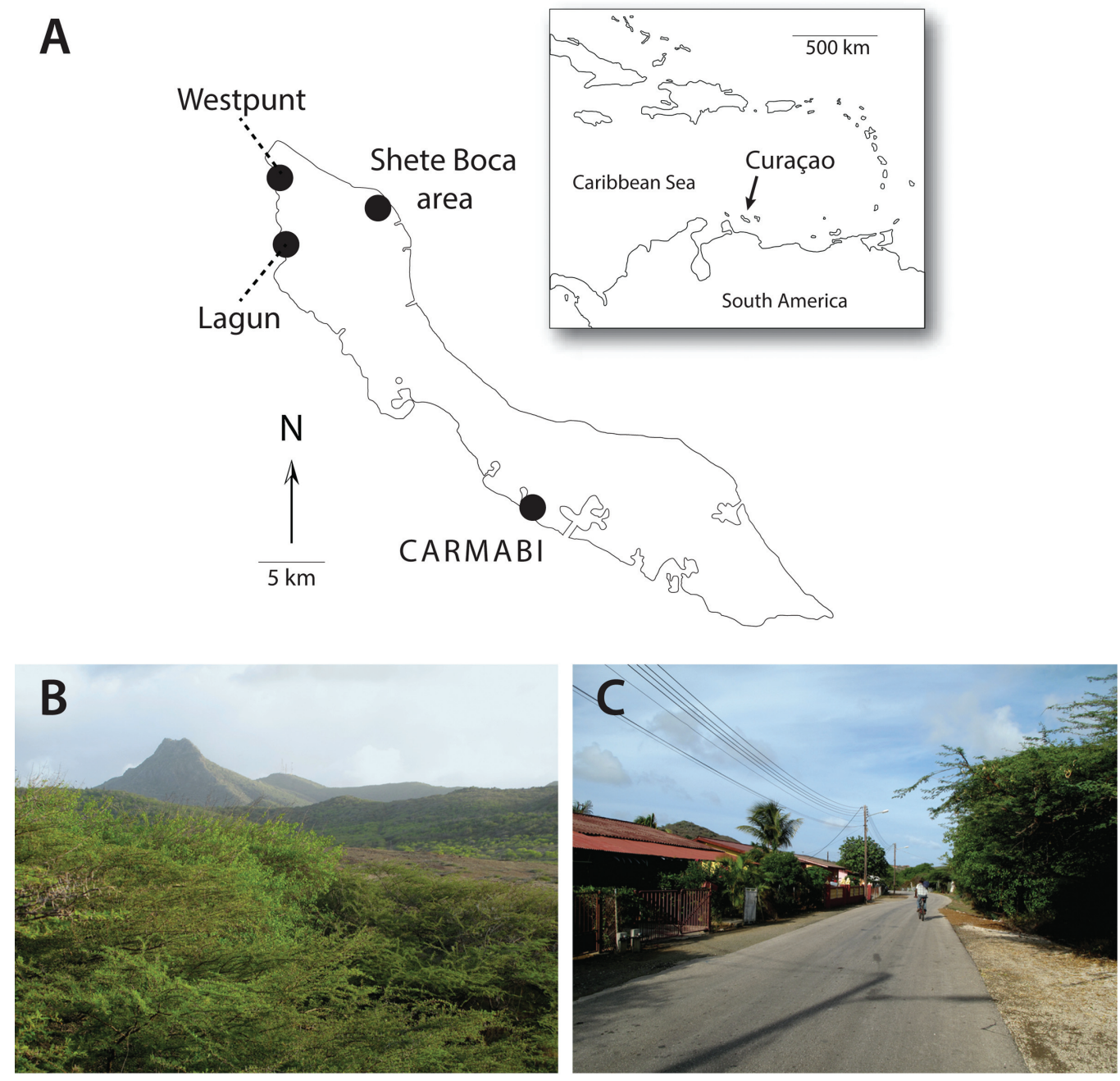

FIGURE 1. Overview of study area. A, Map of sites sampled in this study (redrawn from Dornburg et al. 2011). B, Photograph characterizing the habitat in undeveloped sites. C, Photograph characterizing the habitat in developed sites. Abbreviation: CARMABI, Caribbean Research and Management of Biodiversity.

ties (Clarke 1993). We tested for significant differences between these groupings by subjecting stomach contents to an analysis of similarity (ANOSIM; Clarke 1993; Chapman and Underwood 1999) using Bray-Curtis distances and 999 permutations in the vegan software package (Oksanen et al. 2007; Oksanen 2011). Differences in mean ranks were quantified using the $R$ statistic, with values close to zero indicating high similarity and values close to one indicating high dissimilarity (Chapman and Underwood 1999).

Because this analysis can potentially mask whether a small subset of prey items occurs at a higher or lower frequency than expected by chance, we also conducted a series of simulations to assess if differences in percent frequency are outside of the expectations of stochastic sampling. For each site, we simulated a data set with identical numbers of individuals and randomly assigned between one and three stomach content items to mirror the variance of prey items in a given stomach from our empirical samples. Items were also randomly drawn from a candidate pool of all stomach contents. This simulation was repeated 5,000 times per population, and the distribution of each stomach item's percent frequency was com- 
pared to the empirically calculated frequency to assess significance. Because of the low sample size collected at Lagun ( $n=7)$, ANOSIM and simulation analyses were limited to comparisons between samples collected in Westpunt and the vicinity of Shete Boca.

\section{Morphometric Analyses}

To test for sexual dimorphism in Phyllodactylus martini, we followed the procedure used by Manicom et al. (2014). Briefly, we used an iterative analysis of covariance with each morphometric measurement as a factor, keeping SVL as the covariate. Data were $\log _{10}$ transformed, and assumptions of normality were tested using a Shapiro-Wilk test (Shapiro and Wilk 1965). This allowed us to simultaneously test for a potential correlation with each measured trait and SVL; whether there are significant differences between male and female trait values when accounting for a potential correlation with SVL; and whether there is a significant interaction between SVL and sex, which would indicate one sex is consistently larger than the other for a given trait.

We further tested for correlations between aspects of diet and phenotype using linear regressions between the $\log _{10}$-transformed morphometric trait values and NMDS axes. Trait values were first regressed against SVL, and the residuals of each trait were used in an iterative series of linear regressions between each size-corrected trait and the two NMDS axes. Because preliminary analyses indicated no differences between the sexes, these were pooled for the regression analysis. Conducting a principal components analysis and removing the axis that correlates with body size is a commonly used alternative to controlling for body size in linear measurements (McCoy et al. 2006), but this approach has recently been criticized as potentially misleading in both simulation and empirical data sets. Regression-based analyses, however, which allow covariance with body size, seem more robust to statistical artifacts (Berner 2011).

\section{Spatial Analyses}

To quantify how urbanization may influence the movement of Phyllodactylus martini on Curaçao, we constructed a cost surface to infer the probability of dispersal between sites sampled in this study. Resistance-to-movement values were assigned to roads, rivers and percent of urbanized in contrast to natural habitat at a scale of square kilometers to create a cost surface in ArcGIS, v. 10.0 (ESRI 2016) using data layers compiled from the DIVAGIS database, v. 7.5 (Hijmans et al. 2012) and the 2012 MODIS-based maximum green vegetation fraction from the U.S. Geological Survey Land Cover Institute (http://landcover.usgs.gov/green veg.php; Broxton et al. 2014). Although this spatial scale is potentially coarse for studies of small organisms, this represents the finest-scale data currently available for the island of Curaçao. Additionally, this scale provides a broad assessment of urbanization that can provide the framework for future studies of areas within the island as data layers with increased resolution become available. Based on the natural history of $P$. martini (Van Buurt 2005), as well as mortality studies of other gecko species (Das et al. 2007; Schutt 2008; Wotherspoon and Burgin 2011), rivers, roads and urbanized areas were weighted as difficult to pass through, whereas the natural arid bush habitat (mondi) of the island was given the lowest resistance (Appendix 2). Although P. martini will readily colonize walls, this coding of resistance reflects findings by Hughes et al. (2015), who found this species to be absent in urban areas away from edge habitats. Using the resistance surface, we calculated the shortest cost path distances between all pair localities using the Landscape Genetics toolbox (Etherington 2011), which calculates the pairwise least cost paths among multiple points in ArcGIS. We then tested for a correlation between geographic distance and landscape resistance in limiting potential dispersal between sampled localities, by computing a matrix of the Euclidean distances between points and testing for correlation between this and the resistance matrix using a Mantel test, based on Pearson's product-moment correlation and 999 permutations, in the vegan package of $\mathrm{R}$ (Oksanen et al. 2007). To visualize the cost surface and potential dispersal pathways, we used the CIRCUITSCAPE software package, v. 4.0 (McRae and Beier 2007).

\section{Results}

\section{Stomach Content Analyses}

Seventy-two specimens were dissected, with between 1 and 3 items found per specimen 


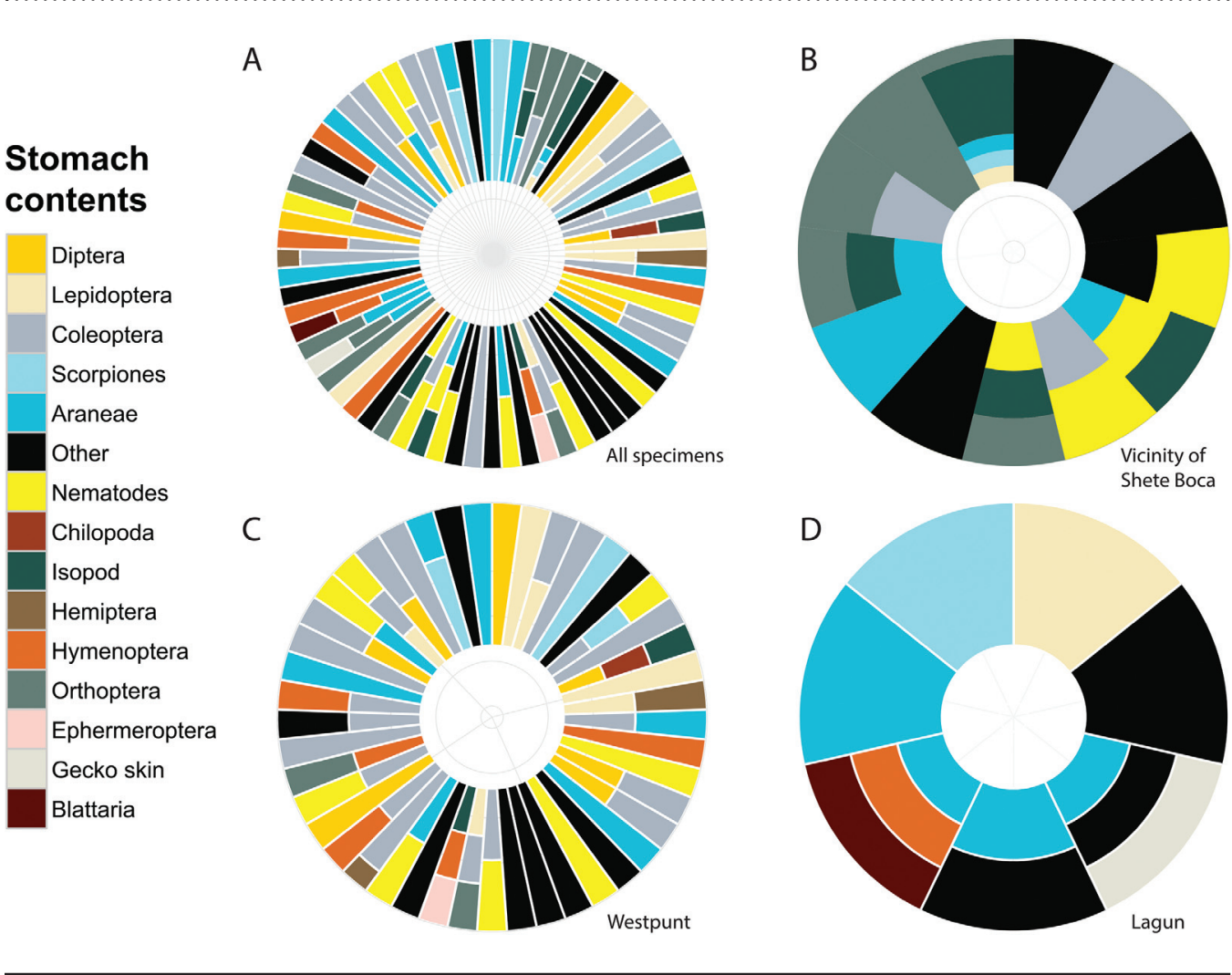

FIGURE 2. Visualizations of the stomach content data. A, From all individuals. B, Samples collected in the vicinity of Shete Boca $(n=13)$. C, Samples collected in Westpunt $(n=45)$. D, Samples collected in Lagun $(n=7)$. Colors correspond to prey items in the legend, and slices in each sphere correspond to the stomach contents of an individual specimen.

(Figure 2). In total, 126 items were recovered, suggesting that Phyllodactylus martini consumes a broad diversity of prey items, with beetles (Coleoptera, 20\%) and spiders (Araneae, 13\%; Table 1; Figure 2A) at the highest frequency. Nematodes were observed in high numbers, accounting for $9 \%$ of all stomach items. Although this rate of infection is similar to background infection rates of $P$. martini stomach nematodes in Bonaire (approximately 12\%; Goldberg et al. 2014) and suggests that parasitic infections are not uncommon, we cannot rule out the possibility that some of these represent parasites from prey items. Comparing samples from Westpunt with those collected in the vicinity of Shete Boca suggests that in developed sites there is a shift toward consumption of more dipterans, lepidopterans, and hemipterans while maintaining a high degree of overlap. In the population near Shete Boca, $P$. martini individuals consumed a high frequency of orthopterans (17\%) and isopods (27\%; Table 1; Figure $2 \mathrm{~B}$ ). In contrast, orthopterans and isopods were found at a much lower frequency in the Westpunt population (each approximately $2 \%$; Table 1; Figure 2C), with coleopterans instead accounting for about $30 \%$ of all items (Table 1; Figure 1). Isopods were also absent from the samples collected at Lagun, where the stomach contents reflected a high frequency of predation on araneaens (Table 1; Figure 2D). Relative to the vicinity of Shete Boca, Westpunt-collected geckos also contained a higher frequency of dipterans ( $11 \%$ in contrast to $6 \%)$ and lepidopterans ( $11 \%$ in contrast to $3 \%$ ), possibly reflecting the tendency for these groups to aggregate under artificial lighting.

Stress values were below 0.015 for all NMDS analyses, suggesting that dissimilarities between groups were adequately captured. NMDS-based visualizations of the gut contents between male 
TABLE 1. Percentage of frequency occurrence of stomach contents found in Phyllodactylus martini across three sites. Abbreviations: $\mu$, number of total items found in all guts at a sampling locality; $n$, number of individuals captured.

\begin{tabular}{lcccc}
\hline Item & All specimens & $\begin{array}{c}\text { Vicinity of Shete Boca } \\
(\boldsymbol{n}=\mathbf{1 3} ; \boldsymbol{\mu}=\mathbf{3 0})\end{array}$ & $\begin{array}{c}\text { Westpunt } \\
(\boldsymbol{n}=\mathbf{4 5}, \boldsymbol{\mu}=\mathbf{8 2})\end{array}$ & $\begin{array}{c}\text { Lagun } \\
(\boldsymbol{n}=\mathbf{7}, \boldsymbol{\mu}=\mathbf{1 4})\end{array}$ \\
\hline Araneae & 0.13 & 0.13 & 0.09 & 0.43 \\
Blattaria & $>0.01$ & - & - & 0.07 \\
Chilopoda & $>0.01$ & - & 0.01 & - \\
Coleoptera & 0.20 & 0.1 & 0.29 & - \\
Diptera & 0.06 & - & 0.11 & - \\
Ephermeroptera & $>0.01$ & - & 0.01 & - \\
Gecko skin & $>0.01$ & - & - & - \\
Hemiptera & 0.015 & - & 0.02 & - \\
Hymenoptera & 0.06 & - & 0.02 & - \\
Isopod & 0.07 & 0.27 & 0.02 & - \\
Lepidoptera & 0.08 & 0.03 & 0.11 & - \\
Nematodes & 0.09 & 0.13 & 0.10 & 0.07 \\
Scorpiones & 0.04 & 0.03 & 0.05 & 0.21 \\
Orthoptera & 0.07 & 0.17 & 0.02 & - \\
Other & 0.10 & 0.13 & 0.10 &
\end{tabular}

and female Phyllodactylus martini in the vicinity of Shete Boca suggests a large degree of overlap, with slightly larger resource use for females (Figure $3 \mathrm{~A}$ ). This trend is reversed in the NMDS visualizations of $P$. martini in Westpunt, where there is considerably more overlap and males exhibit a wider resource use (Figure 3A). However, results of ANOSIM analyses did not support significant dissimilarity in diet between sexes for either population (Shete Boca: $R=0.043, p=0.51$; Westpunt: $R=0.01592, p=0.254$ ).

NMDS-based visualizations of stomach contents between developed and undeveloped sites provide evidence for a much wider resource use in developed sites (Figure 3B). This overlap is supported by an ANOSIM analysis that fails to recover significant dissimilarity between these sites $(R=0.02341, p=0.258)$. This pattern is also evident when adding the samples from Lagun to the visualizations (Figure 3B).

Our simulations demonstrate that several prey items are sampled at a higher frequency than would be expected by chance alone. The frequency of isopods and orthopterans in specimens from the Shete Boca area is significantly elevated $(0.0001<p<0.03$; Figure $4 \mathrm{~A})$. In contrast, the simulations detected significantly fewer consumed isopods and orthopterans in Westpunt $(0.012<p<0.011$; Figure 4$)$ and more coleopterans $(p<0.0001$; Figure $4 \mathrm{~B})$. Although this analysis cannot determine whether shifts in feeding ecology are primarily driven by prey preference or changes in availability, our combined results detect a shift in feeding ecology when these animals transition from the mondi to more developed areas.

\section{Morphometric Analyses}

We found a strong correlation between size and all other measured morphometric traits (Table 2). However, our results provide no evidence for sexual dimorphism. We did not find a significant relationship between size-corrected traits and the sex of the specimen or evidence of size differences between the sexes (Table 2). Linear regressions instead revealed two different patterns of correlation between phenotype and diet in the Westpunt and Shete Boca area populations (Figure 5). Within the Westpunt population, we found no significant correlation between phenotype and either of the two NMDS axes (Table 3). In contrast, within the Shete Boca area we found a significant correlation between both femur and fibula length and the first NMDS axis (Table 4), and a significant correlation between head length and the second NMDS axis (Table 4). 


\section{Sampling Site \\ - Shete}

- West Punt

\section{Sex}

- Male

- Female

A

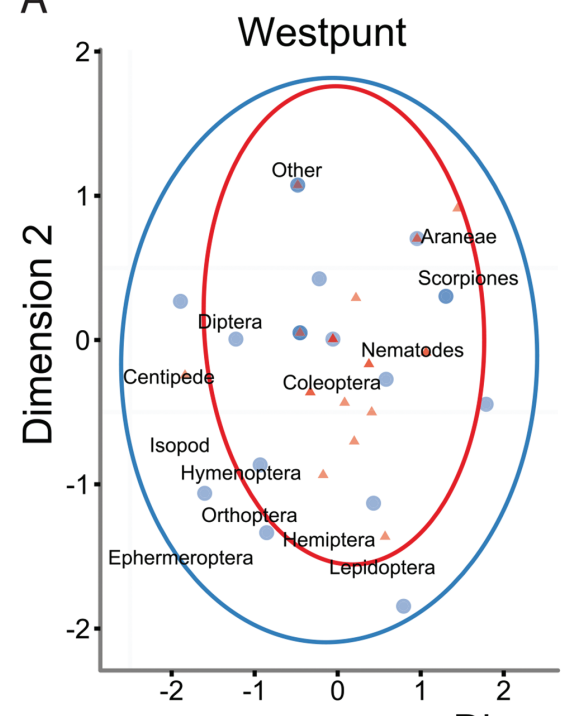

Dimension 1

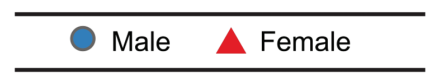

B

2 Sites

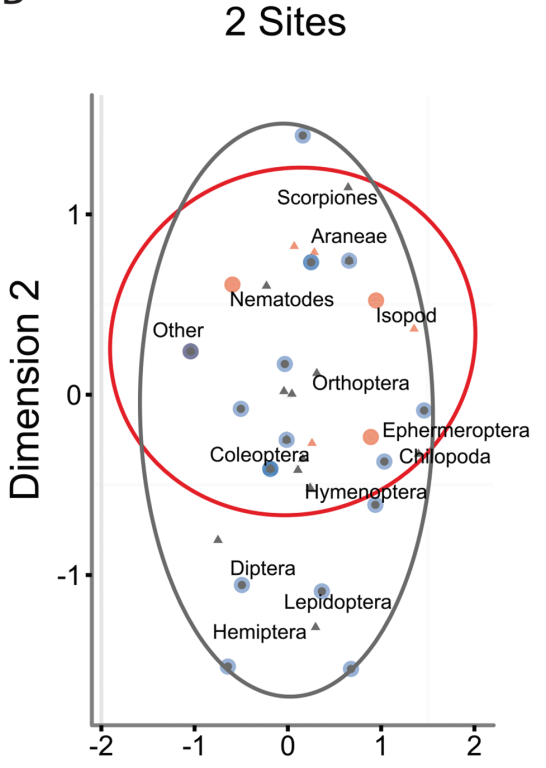

Shete Boca vicinity

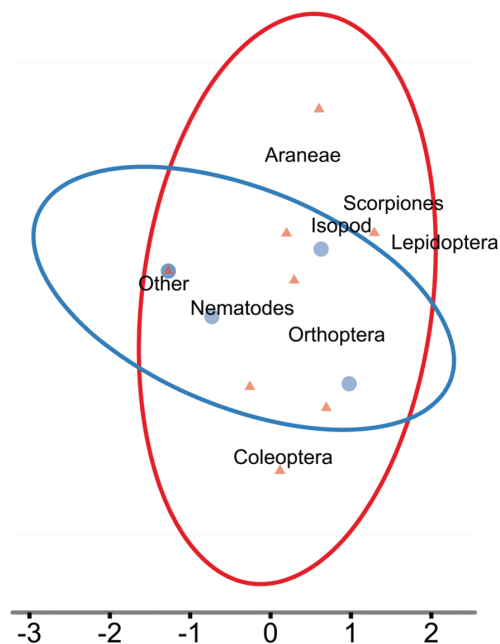

3 Sites

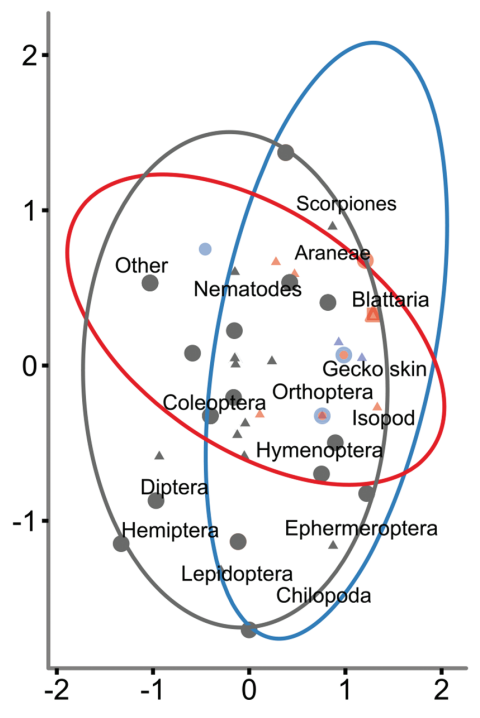

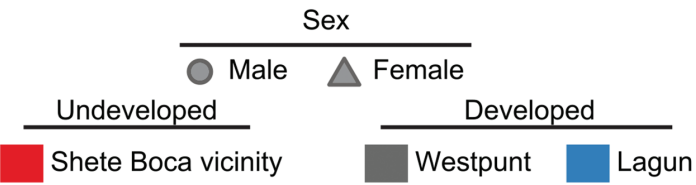

FIGURE 3. Nonmetric multidimensional scaling-based visualizations of stomach contents. A, Comparisons between males and females captured within sites. B, Comparisons between developed and undeveloped sites. 
A

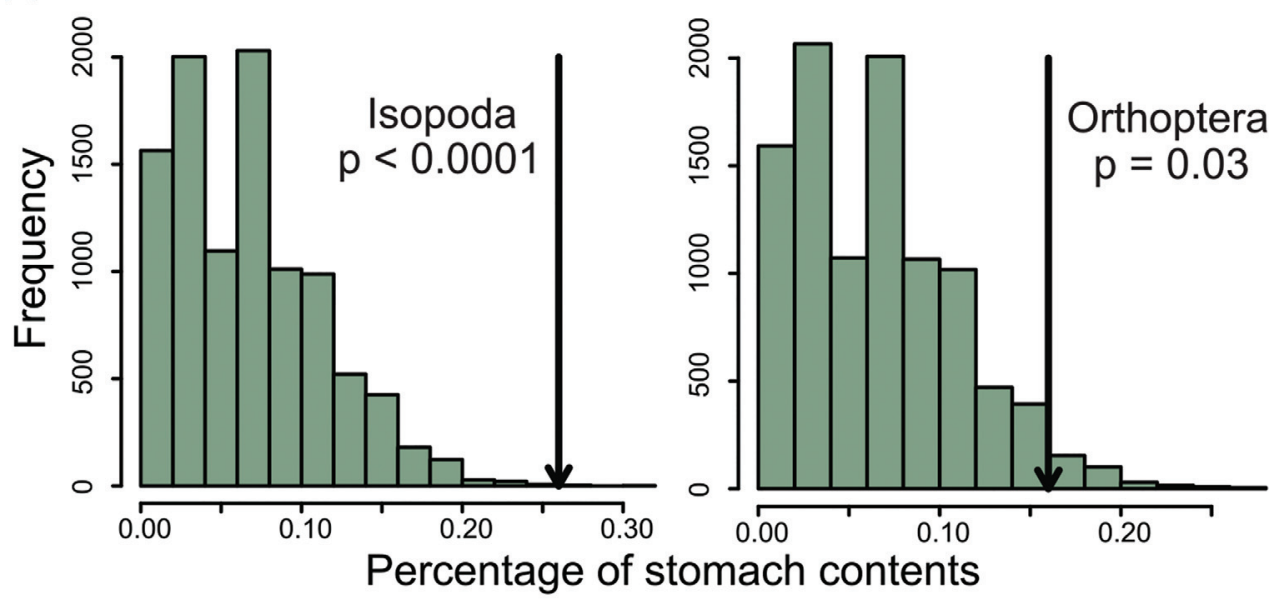

B
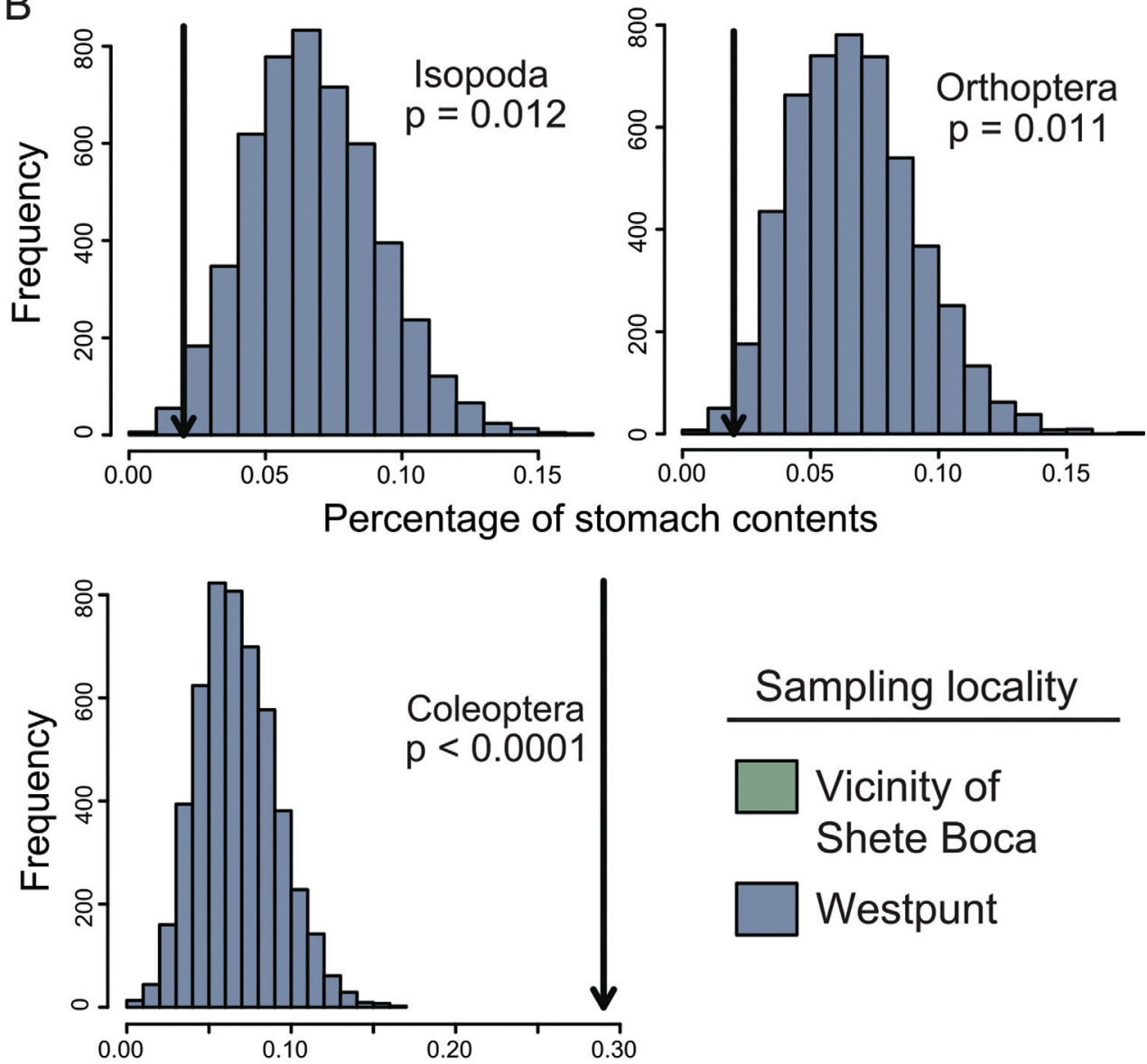

\section{Sampling locality}

Vicinity of

Shete Boca

Percentage of stomach contents

FIGURE 4. Visualizations of stomach content simulations comparing the expected percentage versus empirical percentage. A, For isopods and orthopterans in the vicinity of Shete Boca. B, For isopods, orthopterans and coleopterans in Westpunt. Arrows indicate the percentage of each prey item in the empirical data. 
TABLE 2. Results from an analysis of covariance testing the effect of snout-vent length (SVL), sex and their interaction on measured ecomorphological characters. Values in bold indicate significant effects.

\begin{tabular}{lccc}
\hline Trait & SVL $(\boldsymbol{F}, \boldsymbol{p})$ & Sex $(\boldsymbol{F}, \boldsymbol{p})$ & Sex:SVL $(\boldsymbol{F}, \boldsymbol{p})$ \\
\hline Postorbital width & $\mathbf{4 5 . 7}, \mathbf{1 . 7 e - 8}$ & $0.026,0.87$ & $2.97,0.09$ \\
Temporalis width & $\mathbf{2 3 7 . 3 ,}<\mathbf{2 . 0 e - 1 6}$ & $1.54,0.22$ & $0.31,0.58$ \\
Head length & $\mathbf{2 0 7 . 2 ,}<\mathbf{2 . 0 e - 1 6}$ & $0.26,0.611$ & $0.07,0.79$ \\
Jaw length & $\mathbf{6 4 . 1}, \mathbf{2 . 1 5}-\mathbf{1 5}$ & $0.015,0.82$ & $0.37,0.54$ \\
Head height & $\mathbf{6 2 . 1}, \mathbf{3 . 2 e}-\mathbf{1 0}$ & $0.011,0.91$ & $0.08,0.77$ \\
Humerus length & $\mathbf{5 . 5}, \mathbf{0 . 0 2 3}$ & $0.69,0.41$ & $0.04,0.84$ \\
Ulna length & $\mathbf{6 6 . 2 ,} \mathbf{1 . 3 8 e - 1 0}$ & $0.56,0.45$ & $0.008,0.93$ \\
Femur length & $\mathbf{3 8 . 6}, \mathbf{1 . 2 e - 7}$ & $0.06,0.81$ & $0.80,0.37$ \\
Tibia length & $\mathbf{1 5 . 9 4 , \mathbf { 0 . 0 0 0 2 3 }}$ & $0.54,0.46$ & $1.179,0.28$
\end{tabular}

\section{Spatial Analyses}

Quantification of a resistance surface at a scale of square kilometers suggests the potential for high population connectivity between the Shete Boca area and the northern towns of Lagun and Westpunt (Figure 6). Likewise, dispersal between the areas at the western outskirts of Willemstad near CARMABI research station and the Shete Boca area also requires only a small amount of movement through the high-resistance area (Figure 6). The results of the Mantel test strongly support landscape resistance to be significantly different from Euclidian distances (Mantel statistic 0.9974; $p=0.034)$, suggesting that distance is a greater factor than landscape resistance in limiting dispersal between the sampled areas.

\section{An Observation of Predation on \\ Phyllodactylus martini by \\ Hemidactylus mabouia}

At approximately 23:00 h on 11 September 2011, five of the authors (A.D., A.J., D.L.W., M.C.B. and T.L.I.) observed a juvenile Phyllodactylus martini running across the wall of our laboratory setup on the second floor of Curaçao Sunshine Getaways in Westpunt. This area was open to the outside, and geckos were commonly observed just outside of the window openings or on the living room walls. As the juvenile reached an area above a framed poster hanging on the wall, another gecko rapidly emerged and engulfed the juvenile $P$. martini. We immediately caught this second gecko and identified it as a large (55.7 mm SVL) Hemidactylus mabouia. The tail of the P. martini juvenile was still protruding from the mouth of the captured H. mabouia. We extracted the deceased (31.7 mm SVL) P. martini (YPM HERR 108620) from the H. mabouia (YPM HERR 018631), and both were preserved in formalin and subsequently deposited in the collections of the Yale Peabody Museum. Although H. mabouia has been documented as an opportunistic predator of Gonatodes antillensis on Curaçao (Dornburg et al. 2011), this represents the first documented instance of $H$. mabouia preying on P. martini.

\section{Discussion}

Our study suggests that in Phyllodactylus martini, population decline is not the direct effect of habitat alteration or development but is instead driven by interspecific conflict with the invasive Hemidactylus mabouia. We find that P. martini can switch its feeding and foraging behavior in developed habitats and is able to disperse between developed and undeveloped habitats. Although developed habitats may represent new ecological opportunities for P. martini, this opportunity is limited by the presence of the invasive synanthropic gecko $H$. mabouia. Our observation of predation provides additional evidence that the rapid decline of $P$. martini is linked to a combination of competition (exploitative and interference) and predation. Extrapolating from our results suggests that the presence of Hemidactylus geckos, which are among the most common invasive urban and suburban tropical lizards, enhances the pace of local extinction for toe pad-bearing geckos that would otherwise be able to adapt to at least some level of urban development. 
A SVL

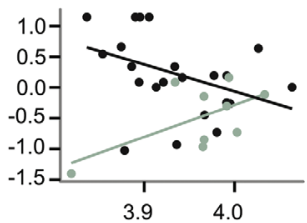

Temporalis width

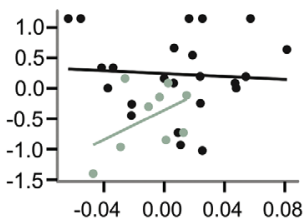

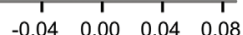

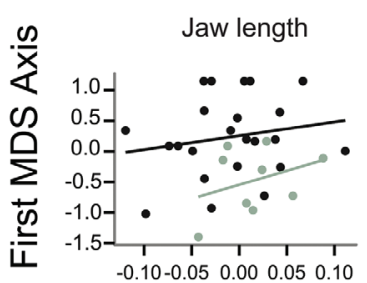

Humerus length

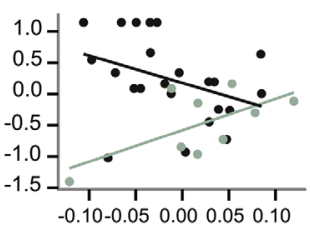

Femur length

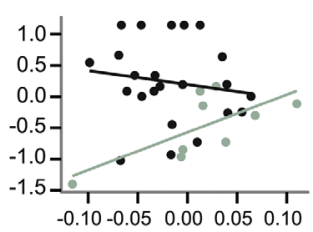

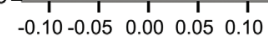

Postorbital width

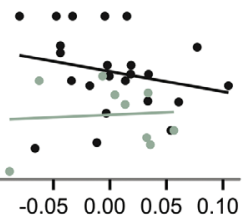

Head length
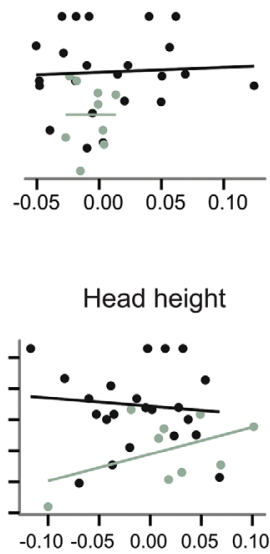

Ulna length

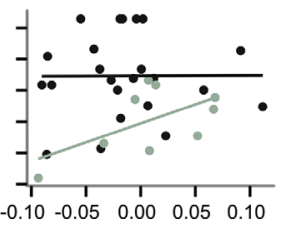

Fibula length

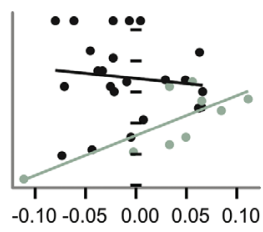

Westpunt
B

SVL

Postorbital width
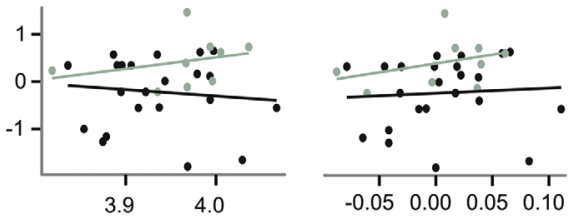

Temporalis width

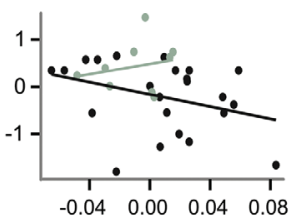

Head length
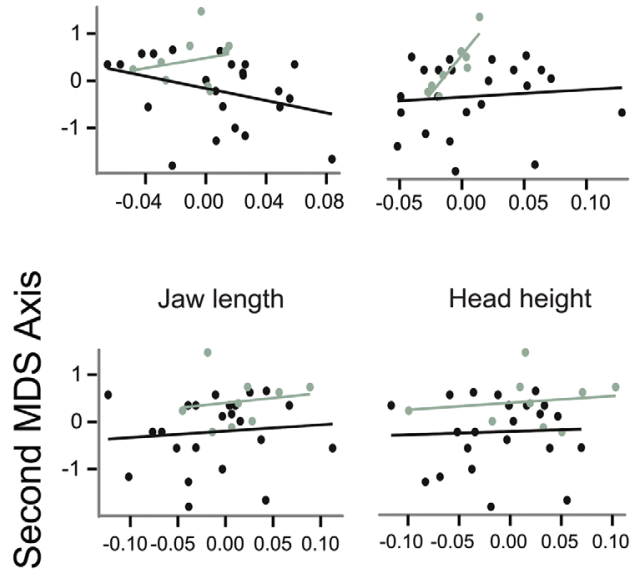

Humerus length

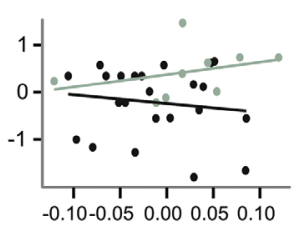

Femur length

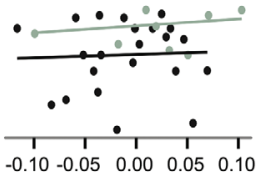

Ulna length

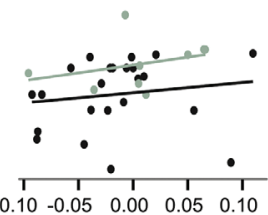

Fibula length
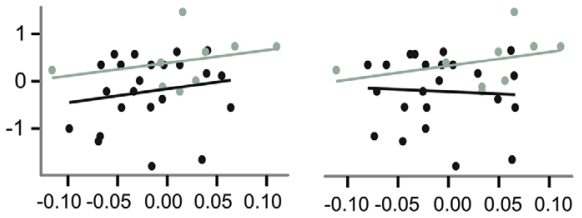

Vicinity of Shete Boca

FIGURE 5. Visualizations of regressions between nonmetric multidimensional scaling (NMDS) axes of diet and phenotype in Westpunt (dark) and Shete Boca (light). A, First NMDS axis. B, Second NMDS axis. Abbreviation: SVL, snout-vent length.

Feeding Plasticity and

Opportunity along an Urban Gradient

The persistence of native wildlife species in urbanizing habitats (synurbanization) often corresponds with major ecological and behavioral shifts (Luniak 2004; McKinney 2006; Pattishall and Cundall 2009; Wang et al. 2015). Our analyses reveal that Phyllodactylus martini portrays a significant shift in consumed prey resources in developed as opposed to undeveloped environments (Figures 2, 3 and 4). Although our sample size encompasses only a small number of individ- 
TABLE 3. Testing for correlations between phenotype and the nonmetric multidimensional scaling (NMDS) axes of stomach contents within the Westpunt population.

\begin{tabular}{lcc}
\hline Trait & $\begin{array}{c}\text { NMDS1 } \\
(\boldsymbol{F}, \boldsymbol{p})\end{array}$ & $\begin{array}{c}\text { NMDS2 } \\
(\boldsymbol{F}, \boldsymbol{p})\end{array}$ \\
\hline Snout-vent length & $3.638,0.070$ & $0.2417,0.628$ \\
Postorbital width & $1.186,0.288$ & $0.0977,0.757$ \\
Temporalis width & $0.096,0.759$ & $2.709,0.114$ \\
Head length & $0.064,0.801$ & $0.2064,0.654$ \\
Jaw length & $0.728,0.403$ & $0.2092,0.652$ \\
Head height & $0.193,0.664$ & $0.0423,0.838$ \\
Humerus length & $3.259,0.085$ & $0.4041,0.531$ \\
Ulna length & $0.8 \mathrm{e}-3,0.97$ & $0.4871,0.492$ \\
Femur length & $0.4814,0.495$ & $0.6487,0.429$ \\
Fibula length & $0.2861,0.598$ & $0.0721,0.790$
\end{tabular}

TABLE 4. Testing for correlations between phenotype and the nonmetric multidimensional scaling (NMDS) axes of stomach contents within the population residing in the vicinity of Shete Boca. Bold text indicates $p$ values below 0.05 .

\begin{tabular}{lcc}
\hline Trait & $\begin{array}{c}\text { NMDS1 } \\
(\boldsymbol{F}, \boldsymbol{p})\end{array}$ & $\begin{array}{c}\text { NMDS2 } \\
(\boldsymbol{F}, \boldsymbol{p})\end{array}$ \\
\hline Snout-vent length & $3.851,0.090$ & $0.6108,0.460$ \\
Postorbital width & $0.0369,0.853$ & $0.9736,0.356$ \\
Temporalis width & $1.978,0.2024$ & $0.3558,0.569$ \\
Head length & $1.6 \mathrm{e}-6,0.999$ & $\mathbf{2 8 , 0 . 0 0 1}$ \\
Jaw length & $0.8961,0.375$ & $0.1889,0.677$ \\
Head height & $1.881,0.212$ & $0.1850,0.680$ \\
Humerus length & $4.691,0.067$ & $0.8822,0.378$ \\
Ulna length & $3.604,0.099$ & $0.8183,0.395$ \\
Femur length & $\mathbf{6 . 5 8 , 0 . 0 3 7}$ & $0.7920,0.403$ \\
Fibula length & $\mathbf{9 . 9 , 0 . 0 1 6 2}$ & $1.01,0.348$
\end{tabular}

uals in a small portion of the island, the shift in resources coupled with the observation that this species readily colonizes walls (Van Buurt 2005, 2006; Hughes et al. 2015) suggests that feeding and foraging behavior in P. martini is quite plastic. Low to moderate levels of development may in fact be providing P. martini with novel ecological opportunities.

Urban development often results in a fundamental transformation of an environment (Luniak 2004). Although detrimental for many taxa, this resetting of the local ecological stage is also expected to create novel niches and ecological opportunities (Gloor et al. 2001; Luniak 2004) in a fashion similar to natural processes such as the colonization of islands or movements of glaciers (Harmon et al. 2008; Parent and Crespi 2009; Near et al. 2012; Federman et al. 2015). Toe pad-bearing gecko species like Phyllodactylus martini can readily invade the smooth vertical surfaces of human dwellings (Autumn et al. 2002; Autumn et al. 2006; Tian et al. 2006); however, it is unclear how the urban and rural invertebrate communities that provide their prey base differ. Urbanization is generally associated with a restructuring of the invertebrate community (Frankie and Ehler 1978; McIntyre 2000; Shochat et al. 2004; Raupp et al. 2010; Sattler et al. 2010). The study of prey resources along urban gradients, and how they change selective pressures on the feeding ecology of predators, therefore, represents an exciting frontier in the urban ecology of the southern Caribbean.

In Phyllodactylus martini, transitions to foraging on anthropogenic walls correlated with a shift away from prey items such as isopods and orthopterans in developed habitats (Figure 4). This shift suggests that $P$. martini spends less time foraging terrestrially or that terrestrial prey resources in urbanized habitats are more limited. Although it is difficult to determine whether one, or both, of these hypotheses explains the abundance of terrestrial arthropods in the diet of urbanized P. martini, this raises the question of whether resource use is correlated with phenotypic variation in ecomorphologically relevant traits. Hind limb morphology and diet for geckos at Shete Boca were significantly related (Table 4); however, no such association was found in Westpunt (Table 3). Longer hind limbs are associated with increased terrestrial sprint speeds in geckos (Zaaf and Van Damme 2001; Cameron et al. 2013). Longer-limbed geckos at Shete Boca seem to frequently prey on terrestrial isopods, suggesting that foraging behaviors may change in response to urbanization. However, long limbs decrease locomotor performance for wall-foraging geckos (Zaaf and Van Damme 2001). The increased locomotor performance of shorter limbs on walls suggests that urbanized $P$. martini may be under selective pressures that limit the natural range of ecomor- 
phological variation in the species. As urbanization has been found to drive rapid evolution in other species (Winchell et al. 2016), further research is clearly warranted.

\section{Are Suburban Invasions Promoting} the Decline of Phyllodactylus martini? For many reptile species, competition with nonnative reptiles has been found to drive population declines (Case and Bolger 1991; Case et al. 1994; Petren and Case 1996; Gibbons et al. 2000; Cole et al. 2005). In particular, exploitative competition has been demonstrated to be a major driver of population declines of native geckos in other areas facing Hemidactylus invasions. It is possible that the shift in diet by Phyllodactylus martini in developed habitats (Figures 2, 3 and 4) overlaps with the diet of H. mabouia, which is largely composed of arthropod prey items in the orders Diptera, Hemiptera and Araneae in urban environments throughout the world (Zamprogno and Teixeira 1998; Meshaka 2000; Bonfiglio et al. 2006; Iturriaga and Marrero 2013). Hemidactylus geckos seem to be particularly efficient at harvesting spatially aggregated resources (Petren and Case 1996), and in areas of Curaçao where both $H$. mabouia and P. martini occur, H. mabouia has been found to be more abundant near light sources that aggregate arthropods (Hughes et al. 2015). In addition to being potentially more efficient at harvesting spatially aggregated resources, H. mabouia may also be limiting access to food resources through territorial interactions.

Hemidactylus mabouia is highly aggressive, and the defense of territories by this species has been linked to the decline of other gecko species in Florida (Meshaka et al 2006; Short and Petren 2012). Following the colonization of $H$. mabouia on structures previously colonized by Phyllodactylus martini in Curaçao, the latter species becomes noticeably absent (Van Buurt 2010; Hughes et al. 2015). This suggests that interference competition may also be limiting the persistence of $P$. martini in developed habitats. As we demonstrate that $P$. martini exhibits no sexual size dimorphism or dimorphism of ecomorphological traits associated with territoriality or foraging (Table 2), this implies that interference competition is likely to affect both sexes equally. Although we cannot rule out the hypothesis that $H$. mabouia may promote sex-specific differences in foraging behavior, nei-

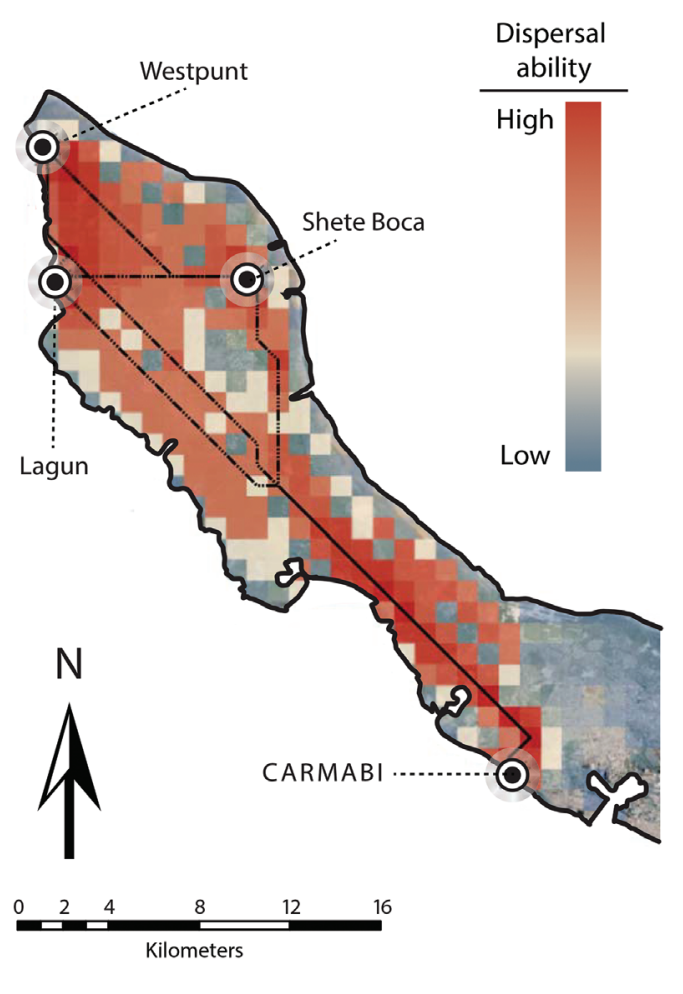

FIGURE 6. A satellite image of Curaçao depicting predicted Phyllodactylus martini dispersal abilities through the study area. Black labeled circles are collection sites; black dotted lines show the least cost pathways among localities; colors represent a resistance gradient of dispersal ability with red being high dispersal probability and blue being low. Areas of least resistance and shortest least cost path correspond to those areas experiencing the least urbanization. Abbreviation: CARMABI, Caribbean Research and Management of Biodiversity.

ther our study nor others documenting the decline of $P$. martini have provided sufficient evidence in favor of this hypothesis (Hughes et al. 2015). Although the combination of interference and exploitative competition may explain the decline of $P$. martini in urban areas, the rate at which $H$. mabouia displaces other gecko species exceeds the theoretical expectations of displacement by competition alone (Short and Petren 2012).

Our observation of predation on a juvenile Phyllodactylus martini by Hemidactylus mabouia suggests another factor influencing the decline of P. martini on Curaçao. Predation on native juvenile lizards by an invading lizard has been repeat- 
edly documented across several species. For example, within Anolis lizards, A. sagrei has been shown to prey on juvenile $A$. carolinensis in Florida and A. conspersus in the Grand Cayman (Gerber and Echternacht 2000). Within geckos, predation on juvenile Lepidodactylus lugubris by $H$. frenatus has been demonstrated experimentally and has been proposed as a potential factor contributing to displacement of $L$. lugubris (Frogner 1967; Bolger and Case 1992; Case et al. 1994). However, gut content analysis of $H$. frenatus could not verify that this behavior was occurring in the wild (Bolger and Case 1992). Our observation coupled with a documented instance of predation by H. mabouia on Gonatodes antillensis (Dornburg et al. 2011) raises the possibility that H. mabouia is opportunistically saurophagous. Therefore, in addition to both exploitative and interference competition, predation is likely at least partially contributing to the displacement of $P$. martini.

Although Hemidactylus mabouia cannot survive in the harsh arid habitat that characterizes the island, the species is ubiquitous in urban and semiurban habitats (Van Buurt 2005). This geographic pattern raises the potential that, as in other biological invasions, suburban landscapes provide invasion "stepping stones" across the landscape for H. mabouia (McKinney and Lockwood 1999). Integrating our spatial and ecomorphological results with this finding, we can speculate that the continued connectivity of native habitat throughout the northern two-thirds of the island will be critical to ensuring gene flow between populations of Phyllodactylus martini. However, this is based on both a coarse analysis of connectivity and the assumption that these reptiles readily disperse to new areas. A recent study in another species of Phyllodactylus inhabiting the dry forests of Mexico suggests that the presence of $H$. mabouia in developed habitats may dramatically alter dispersal pathways and hasten population fragmentation (Blair et al. 2015). Although our spatial analyses suggest high connectivity between undisturbed habitats north of CARMABI research station and the western portion of Willemstad (Figure 6), further study of $H$. mabouia using landscape genetic approaches and sampling from across its range will be fundamental in illuminating the conservation needs of this species.

\section{Conclusions}

Predicting the effect of urbanization on the persistence of native, cryptic animals in biodiversity hot spots presents a major challenge to conservation biology in the 21st century. Our study suggests that moderate levels of urbanization may not promote the decline of Phyllodactylus martini as both male and females of this gecko species seem to alter their diet and foraging behavior in urban habitats. However, our findings posit that the invasive Hemidactylus mabouia in semiurbanized and urbanized areas may drive the decline of $P$. martini through competition and predation. Hemidactylus geckos have invaded suburban habitats in the tropics and subtropics globally, and our findings may be illustrative of a global conservation concern for toe pad-bearing geckos. Despite the potential ecological opportunities in suburban habitats for wall-climbing geckos, these habitats may in fact serve as points of invasion for nonnative species and set the stage for homogenization of the urban reptile community (e.g., With 2004; Blair and Johnson 2008). Given the increased anthropogenic pressures on many of the world's tropical biodiversity hot spots, further investigating the ecological and population dynamics of these less commonly observed species in semideveloped habitats will be critical in understanding their conservation needs.

\section{Acknowledgments}

We thank Mark Vermeij and the entire staff of CARMABI for facilitating collection efforts and export permitting, and Sunshine and David at Curaçao Sunshine Getaways for allowing us to convert the second floor of their home into a field station. We also thank the Westpunt Syndicate for their advice and help in the field. We thank T. Near and three anonymous reviewers for helpful comments on an earlier version of this paper. Specimens were collected under the approved guidelines of IACUC (Institutional Animal Care and Use Committee) protocol 2012-10681 (Ichthyology and Herpetology at the Yale Peabody Museum of Natural History). All data have been archived on Zenodo (doi:10.5281/zenodo.61569).

Received 13 January 2016; revised and accepted 14 June 2016. 


\section{Appendix 1 Specimens of Curaçao Phyllodactylus martini}

Specimens of Curaçao Phyllodactylus martini examined for stomach contents and morphometric analysis, by locality. Abbreviations: CARMABI, Caribbean Research and Management of Biodiversity; YPM HERR, Division of Vertebrate Zoology Herpetology Collection (Reptiles), Peabody Museum of Natural History, Yale University.

\section{CARMABI}

YPM HERR 018435, 018436, 018437

\section{Lagun}

YPM HERR 018461, 018462, 018463, 018466, 018467, 018468

\section{Shete Boca}

YPM HERR 018342, 018343, 018344, 018345, 018346, 018347, 018348, 018349, 018624, 018625, 018626, 018627, 018628, 018629

\section{Westpunt}

YPM HERR 017585, 017586, 017587, 017588, 017589, 017590, 017591, 017592, 017593, 017594, 017595, 017596, 017597, 017598, 017599, 017600, 017601, 017602, 017605, 017607, 018141, 018165, 018166, 018167, 018168, 018169, 018170, 018171, 018172, 018173, 018174, 018175, 018176, 018177, 018178, 018179, 018180, 018181, 018183, 018184, 018185, 018186, 018187, 018611, 018612, 018613, 018614, $018615,018616,018617,018618,018619,018620$, $018621,018622,018623,018645,018646$

\begin{tabular}{|c|c|c|}
\hline $\begin{array}{r}\text { Resistar } \\
\text { Sp }\end{array}$ & $\begin{array}{l}\text { Appendix } 2 \\
\text { ace Values Usec } \\
\text { atial Analyses }\end{array}$ & for \\
\hline & Land cover class & Resistance ${ }^{b}$ \\
\hline Forest cover $(\%)^{a}$ & $89-100$ & 1 \\
\hline & $73-89$ & 2 \\
\hline & $53-73$ & 4 \\
\hline & $31-53$ & 6 \\
\hline & $10-31$ & 8 \\
\hline & $0-10$ & 10 \\
\hline Road & Present & 10 \\
\hline & Absent & 1 \\
\hline River & Present & 10 \\
\hline & Absent & 1 \\
\hline $\begin{array}{l}\text { a Forest cover was d } \\
\text { into six categories } u\end{array}$ & $\begin{array}{l}\text { ivided according to } \\
\text { ing ArcGIS, v. 10.0. }\end{array}$ & natural breaks \\
\hline $\begin{array}{l}\text { b Resistance to move } \\
\text { numbers represent } \\
\text { numbers represent }\end{array}$ & $\begin{array}{l}\text { ment across a surfa } \\
\text { difficulty of move } \\
\text { ase of movement. }\end{array}$ & $\begin{array}{l}\text { ce, where high } \\
\text { ment and low }\end{array}$ \\
\hline
\end{tabular}

\section{Literature Cited}

Autumn, K., S.T. Hsieh, D.M. Dudek, J. Chen, C. Chitaphan AND R.J. FULL. 2006. Dynamics of geckos running vertically. Journal of Experimental Biology 209(2):260-272.

Autumn, K., M. Sitti, Y.A. Liang, A.M. Peattie, W.R. Hansen, S. Sponberg, T.W. Kenny, R. Fearing, J.N. ISRAELACHVILI AND R.J. FULL. 2002. Evidence for van der Waals adhesion in gecko setae. Proceedings of the National Academy of Sciences of the United States of America 99(19):12252-12256.

BERNER, D. 2011. Size correction in biology: How reliable are approaches based on (common) principal component analysis? Oecologia 166(4):961-971.

Blair, C., V.H.J. ARCOS, F.R.M. DE LA CRUZ AND R.W. MURPHY. 2015. Historical and contemporary demography of leaftoed geckos (Phyllodactylidae: Phyllodactylus tuberculosus saxatilis) in the Mexican dry forest. Conservation Genetics 16(2):419-429.

Blair, R.B. AND E.M. JOHNSON. 2008. Suburban habitats and their role for birds in the urban-rural habitat network: Points of local invasion and extinction? Landscape Ecology 23(10):1157-1169.

BOLGER, D.T. AND T.J. CASE. 1992. Intra- and interspecific interference behaviour among sexual and asexual geckos. Animal Behaviour 44(1):21-30.

Bonfiglio, F., R.L. BALESTRIN ANd L.H. CAPPEllari. 2006. Diet of Hemidactylus mabouia (Sauria, Gekkonidae) in urban area of southern Brazil. Biociências 14(2):107111.

BROOK, B.W., N.S. SodHI AND C.J.A. BRADSHAW. 2008. Synergies among extinction drivers under global change. Trends in Ecology \& Evolution 23(8):453-460.

Brooks, T.M., R.A. MitTermeier, C.G. MitTermeier, G.A.B. Da Fonseca, A.B. Rylands, W.R. Konstant, P. Flick, ET AL. 2002. Habitat loss and extinction in the hotspots of biodiversity. Conservation Biology 16(4):909-923.

Broxton, P.D., X. Zeng, W. SCheftic and P.A. Troch. 2014. A MODIS-Based $1 \mathrm{~km}$ Maximum Green Vegetation Fraction Dataset. Journal of Applied Meteorology and Climatology 53(8):1996-2004.

CAmeron, S.F., M.L. Wynn And R.S. WiLSON. 2013. Sex-specific trade-offs and compensatory mechanisms: Bite force and sprint speed pose conflicting demands on the design of geckos (Hemidactylus frenatus). Journal of Experimental Biology 216(2):3781-3789.

CARRANZA, S. AND E.N. ARNOLD. 2006. Systematics, biogeography, and evolution of Hemidactylus geckos (Reptilia: Gekkonidae) elucidated using mitochondrial DNA sequences. Molecular Phylogenetics and Evolution 38(2): 531-545.

Case, T.J. And D.T. Bolger. 1991. The role of introduced species in shaping the distribution and abundance of island reptiles. Evolutionary Ecology 5(3):272-290.

Case, T.J., D.T. Bolger and K. Petren. 1994. Invasions and competitive displacement among house geckos in the tropical Pacific. Ecology 75(2):464-477.

Chapman, M.G. And A.J. Underwood. 1999. Ecological patterns in multivariate assemblages: Information and interpretation of negative values in ANOSIM tests. Marine Ecology Progress Series 180:257-265. 
Cincotta, R.P., J. Wisnewsi and R. Engelman. 2000. Human population in the biodiversity hotspots. Nature 404:990-992.

ClaRKE, K.R. 1993. Non-parametric multivariate analyses of changes in community structure. Australian Journal of Ecology 18(1):117-143.

Cole, N.C., C.G. Jones And S. HaRRIS. 2005. The need for enemy-free space: The impact of an invasive gecko on island endemics. Biological Conservation 125(4):467-474.

Das, A., M.F. Ahmed, B.P. Lahkar and P. Sharma. 2007. A preliminary report of reptilian mortality on road due to vehicular movements near Kaziranga National Park, Assam, India. Zoos' Print Journal 22(7):2742-2744.

Debrot, A.O. 2003. A review of the freshwater fishes of Curaçao, with comments on those of Aruba and Bonaire. Caribbean Journal of Science 39(1):100-108.

DORNBurg, A., D.L. WARREN, T. IgLESIAS AND M.C. BRANDLEY. 2011. Natural history observations of the ichthyological and herpetological fauna on the island of Curaçao (Netherlands). Bulletin of the Peabody Museum of Natural History 52(1):181-186

ECHTERNACHT, A.C. 1999. Possible causes for the rapid decline in population density of green anoles, Anolis carolinensis (Sauria: Polychrotidae) following invasion by the brown anole, Anolis sagrei, in the southeastern United States. Anolis Newsletter 5:22-27.

ESRI. 2016. ArcGIS Spatial Analyst. Version 10.0. Redlands, CA: ESRI. http://www.esri.com/products

ETHERINGTON, T.R. 2011. Python based GIS tools for landscape genetics: Visualising genetic relatedness and measuring landscape connectivity. Methods in Ecology and Evolution 2(1):52-55.

Federman, S., A. Dornburg, A. Downie, A.F. Richard, D.C. DALY AND M.J. DonOGHUE. 2015. The biogeographic origin of a radiation of trees in Madagascar: Implications for the assembly of a tropical forest biome. BMC Evolutionary Biology 15:216.

FISHER, R. AND I. INEICH. 2012. Cryptic extinction of a common Pacific lizard Emoia impar (Squamata, Scincidae) from the Hawaiian Islands. Oryx 46(2):187-195.

Frankie, G.W. AND L.E. EHLER. 1978. Ecology of insects in urban environments. Annual Review of Entomology 23:367-387.

FroGNER, K.J. 1967. Some aspects of the interaction between the gecko species Hemidactylus frenatus and Lepidodactylus lugubris in Hawaii [master's thesis]. Honolulu: University of Hawaii, Department of Zoology.

Garden, J.G., C.A. McAlpine, H.P. Possingham and D.N. JONES. 2007. Habitat structure is more important than vegetation composition for local-level management of native terrestrial reptile and small mammal species living in urban remnants: A case study from Brisbane, Australia. Austral Ecology 32(6):669-685.

Gerber, G.P. AND A.C. Echternacht. 2000. Evidence for asymmetrical intraguild predation between native and introduced Anolis lizards. Oecologia 124(4):599-607.

Gibbons, J.W., D.E. ScotT, T.J. Ryan, K.A. Buhlmann, T.D. Tuberville, B.S. Metts, J.L. Greene, T. Mills, Y. Leiden, S. Poppy and C.T. Winne. 2000. The global decline of reptiles, déjà vu amphibians. BioScience 50(8): 653-666.
GibBS, J.P. And E.J. Stanton. 2001. Habitat fragmentation and arthropod community change: Carrion beetles, phoretic mites, and flies. Ecological Applications 11(1): 79-85.

Gloor, S., F. Bontadina, D. Hegglin, P. Deplazes and U. BREITENMOSER. 2001. The rise of urban fox populations in Switzerland. Mammalian Biology 66:155-164.

GoldberG, S.R., C.R. BurSey, L.J. VitT AND J. Arreola. 2014. Phyllodactylus martini (Dutch leaf-toed gecko) endoparasites. Herpetological Review 45(1):132.

Harmon, L.J., J. Melville, A. Larson and J.B. Losos. 2008. The role of geography and ecological opportunity in the diversification of day geckos (Phelsuma). Systematic Biology 57(4):562-573.

Hijmans, R.J., L. Guarino and P. MathuR. 2012. DIVA-GIS. Version 7.5. Manual. Davis, CA: LizardTech, Inc.; University of California. http://www.diva-gis.org

Hughes, D.F., W.E. MeshaKa JR. AND G. van BuURT. 2015. The superior colonizing gecko Hemidactylus mabouia on Curaçao: Conservation implications for the native gecko Phyllodactylus martini. Journal of Herpetology 49(1):6063.

ItURRIAGA, M. AND R. MARRERo. 2013. Feeding ecology of the Tropical House Gecko Hemidactylus mabouia (Sauria: Gekkonidae) during the dry season in Havana, Cuba. Herpetology Notes 6:11-17.

KLUGE, A.G. 1969. The Evolution and Geographical Origin of the New World Hemidactylus mebouia-brookii Complex (Gekkonidae, Sauria). Ann Arbor: Museum of Zoology, University of Michigan. 78 pp. (Miscellaneous Publications 138.)

KoOPMAN, K.F. 1958. Land bridges and ecology in bat distribution on islands off the northern coast of South America. Evolution 12(4):429-439.

-1959 . The zoogeographical limits of the West Indies. Journal of Mammalogy 40(2):236-240.

KratochVíl, L. AND D. FrYnTA. 2002. Body size, male combat and the evolution of sexual dimorphism in eublepharid geckos (Squamata: Eublepharidae). Biological Journal of the Linnean Society 76(2):303-314.

Kraus, F. 2008. Alien Reptiles and Amphibians: A Scientific Compendium and Analysis. Dordrecht, The Netherlands: Springer.

LIDTH DE JeUde, TH.W. VAN. 1887. On a collection of reptiles and fishes from the West-Indies. Notes from the Leyden Museum 9(1):129-139.

LUNIAK, M. 2004. Synurbization - adaptation of animal wildlife to urban development. In: W.W. Shaw, L.K. Harris and L. Vandruff, eds. Proceedings of the 4th International Symposium on Urban Wildlife Conservation; 1-5 May 1999; Tucson, AZ. Tucson: University of Arizona, School of Natural Resources, College of Agriculture and Life Sciences. pp. 50-55.

Manicom, C., R. Alford, T.W. Schoener and L. SCHWARZKOPF. 2014. Mechanisms causing variation in sexual size dimorphism in three sympatric, congeneric lizards. Ecology 95(6):1531-1544.

MCCOY, M.W., B.M. BOLKer, C.W. OSENBERG, B.G. Miner AND J.R. VONESH. 2006. Size correction: Comparing morphological traits among populations and environments. Oecologia 148(4):547-554. 
McFarlane, D.A. And J. Lundberg. 2002. A middle Pleistocene age and biogeography for the extinct rodent Megalomys curazensis from Curaçao, Netherlands Antilles. Caribbean Journal of Science 38(3-4):278-281.

MCINTYRE, N.E. 2000. Ecology of urban arthropods: A review and a call to action. Annals of the Entomological Society of America 93(4):825-835.

McKinNEY, M.L. 2006. Urbanization as a major cause of biotic homogenization. Biological Conservation 127(3):247-260.

McKinNEY, M.L. AND J.L. LocKwOOD. 1999. Biotic homogenization: A few winners replacing many losers in the next mass extinction. Trends in Ecology \& Evolution 14(11): 450-453.

McRAe, B.H. AND P. BEIER. 2007. Circuit theory predicts gene flow in plant and animal populations. Proceedings of the National Academy of Sciences of the United States of America 104(50):19885-19890.

MESHAKA, W.E., JR. 2000. Colonization dynamics of two exotic geckos (Hemidactylus garnotii and H. mabouia) in Everglades National Park. Journal of Herpetology 34(1):163-168.

MeshaKa, W.E., JR., H.L. CRESS, K.L. KingsLand, H.T. SMith, S.A. FitchetT, J.A. Moore and E.M. CoWAn. 2006. Hemidactylus (house gecko) assemblage dynamics on south Florida buildings. Journal of Kansas Herpetology 17:8-9.

MOREAU DE JONNĖS, A. 1818. Monographie du mabouja des murailles, on Gecko Mabouja des Antilles. Bulletin des Sciences par la Société Philomathique de Paris, Series 3 5:138-139.

Muñoz-Garay, J. and H. Mantilla-Meluk. 2012. First record of Myotis nesopolus from Colombia. Lubbock: Museum of Texas Tech University. (Occasional Papers 312.)

Myers, N., R.A. MitTermeier, C.G. MitTermeier, G.A.B. DA FONSECA AND J. KENT. 2000. Biodiversity hotspots for conservation priorities. Nature 403:853-858.

Near, T.J., A. Dornburg, K.L. Kuhn, J.T. Eastman, J.N. Pennington, T. Patarnello, L. Zane, D.A. FernándeZ and C.D. JONES. 2012. Ancient climate change, antifreeze, and the evolutionary diversification of Antarctic fishes. Proceedings of the National Academy of Sciences of the United States of America 109(9):3434-3439.

OKSANEN, J. 2011. Multivariate Analysis of Ecological Communities in R: vegan Tutorial. R Package, Version 2.4. Vienna, Austria: R Foundation for Statistical Computing. https:// github.com/vegandevs/vegan

OKsanen, J., R. Kindt, P. Legendre, B. O’Hara, and M.H.H. Stevens. 2007. The vegan Package: Community Ecology Package. Vienna, Austria: R Foundation for Statistical Computing.

PARENT, C.E. AND B.J. CRESPI. 2009. Ecological opportunity in adaptive radiation of Galápagos endemic land snails. American Naturalist 174(6):898-905.

Pattishall, A. And D. Cundall. 2009. Habitat use by synurbic watersnakes (Nerodia sipedon). Herpetologica 65(2): 183-198.

PERRY, G. 1996. The evolution of sexual dimorphism in the lizard Anolis polylepis (Iguania): Evidence from intraspecific variation in foraging behavior and diet. Canadian Journal of Zoology 74(7):1238-1245.

Petren, K. And T J. CASE. 1996. An experimental demonstration of exploitation competition in an ongoing invasion. Ecology 77(1):118-132.
Ramírez-Sandoval, E., A. Ramírez-Bautista, L.J. VitT and T.W. REEDER. 2006. Reproduction in the lizard Phyllodactylus lanei (Squamata: Gekkonidae) from the Pacific Coast of Mexico. Copeia 2006(1):1-9.

Raupp, M.J., P.M. Shrewsbury and D.A. Herms. 2010. Ecology of herbivorous arthropods in urban landscapes. Annual Review of Entomology 55:19-38.

Reynolds, R.G. AND M.L. NiemilLER. 2010. Island invaders: Introduced amphibians and reptiles in the Turks and Caicos Islands. IRCF Reptiles \& Amphibians 17(2):117-121.

Rivas, G.A., G.N. Ugueto, W.E. Schargel, T.R. Barros, P. Velozo AND L.E. SÁNCHEZ. 2013. A distinctive new species of Gonatodes (Squamata: Sphaerodactylidae) from Isla La Blanquilla, Venezuela, with remarks on the distribution of some other Caribbean sphaerodactylid lizards. South American Journal of Herpetology 8(1):5-18.

Sattler, T., P. Duelli, M.K. Obrist, R. Arlettaz and M. MORETTI. 2010. Response of arthropod species richness and functional groups to urban habitat structure and management. Landscape Ecology 25(6):941-954.

SCHUTT, P. 2008. Analysis of road kill data from Ankarafantsika National Park, Madagascar [master's thesis]. Durham, NC: Duke University, Nicholas School of the Environment and Earth Sciences.

SETO, K.C., B. GÜNERALP AND L.R. HutYra. 2012. Global forecasts of urban expansion to 2030 and direct impacts on biodiversity and carbon pools. Proceedings of the National Academy of Sciences of the United States of America 109(40):16083-16088.

SHAPIRO, S.S. AND M.B. WILK. 1965. An analysis of variance test for normality (complete samples). Biometrika 52(3/4): 591-611.

Shochat, E., W.L. Stefanov, M.E.A. Whitehouse AND S.H. FAETH. 2004. Urbanization and spider diversity: Influences of human modification of habitat structure and productivity. Ecological Applications 14(1):268-280.

SHort, K.H. And K. Petren. 2012. Rapid species displacement during the invasion of Florida by the tropical house gecko Hemidactylus mabouia. Biological Invasions 14(6):11771186.

SodHI, N.S., L.P. KoH, B.W. BroOK AND P.K.L. NG. 2004. Southeast Asian biodiversity: An impending disaster. Trends in Ecology \& Evolution 19(12):654-660.

Starostová, Z., L. KubičKa and L. KRAtochvíl. 2010. Macroevolutionary pattern of sexual size dimorphism in geckos corresponds to intraspecific temperature-induced variation. Journal of Evolutionary Biology 23(4):670-677.

Staton, M.A. AND J.R. Dixon. 1977. The herpetofauna of the central Llanos of Venezuela: Noteworthy records, a tentative checklist and ecological notes. Journal of Herpetology 11(1):17-24.

Tian, Y., N. Pesika, H. Zeng, K. RosenberG, B. Zhao, P. McGuiggan, K. Autumn and J. Israelachvili. 2006. Adhesion and friction in gecko toe attachment and detachment. Proceedings of the National Academy of Sciences of the United States of America 103(51):19320-19325.

VAN BuURT, G. 2005. Field Guide to the Amphibians and Reptiles of Aruba, Curaçao and Bonaire. Frankfurt am Main, Germany: Edition Chimaira.

-2006. Conservation of amphibians and reptiles in Aruba, Curaçao and Bonaire. Applied Herpetology 3:307-321. 
-2010. A short natural history of Curaçao. In: N. Faraclas, R. Severing, C. Weijer and E. Echteld, eds. Crossing Shifting Boundaries: Language and Changing Political Status in Aruba, Bonaire and Curaçao. Proceedings of the Eastern Caribbean Island Cultures Conference (ECICC), Volume 1; Dominica; 2009. Willemstad, Curaçao: Fundashon pa Planifikashon di Idioma, Universiteit van de Nederlandse Antillen. pp. 229-256.

WANG, Y., Q. Huang, S. LAN, Q. Zhang and S. Chen. 2015. Common blackbirds Turdus merula use anthropogenic structures as nesting sites in an urbanized landscape. Current Zoology 61(3):435-443.

WERNER, Y.L. AND T. SEIFAN. 2006. Eye size in geckos: Asymmetry, allometry, sexual dimorphism, and behavioral correlates. Journal of Morphology 267(12):1486-1500.

Winchell, K.M., R.G. Reynolds, S.R. Prado-IrWin, A.R. Puente-Rolón AND L.J. Revell. 2016. Phenotypic shifts in urban areas in the tropical lizard Anolis cristatellus. Evolution 70(5):1009-1022.

WiTH, K.A. 2004. Assessing the risk of invasive spread in fragmented landscapes. Risk Analysis 24(4):803-815.

WOTHERSPOON, D. AND S. BURGIN. 2011. The impact on native herpetofauna due to traffic collision at the interface between a suburban area and the Greater Blue Mountains World
Heritage Area: An ecological disaster? Australian Zoologist 35(4):1040-1046.

WÜster, W., J.E. Ferguson, J.A. Quijada-Mascareñas, C.E. Pook, M. Da Graça Salomão and R.S. Thorpe. 2005. Tracing an invasion: Landbridges, refugia, and the phylogeography of the Neotropical rattlesnake (Serpentes: Viperidae: Crotalus durissus). Molecular Ecology 14(4):1095-1108.

ZAAF, A. AND R. VAN DAMme. 2001. Limb proportions in climbing and ground-dwelling geckos (Lepidosauria, Gekkonidae): A phylogenetically informed analysis. Zoomorphology 121(1):45-53.

Zamprogno, C. and R. Teixeira. 1998. Food habits of the tropical house gecko Hemidactylus mabouia (Reptilia, Gekkonidae) from a sandy coastal plain of Espirito Santo, eastern Brazil. Revista Brasileira de Biologia 58(1): 143-150.

ZavaleTA, E.S., R.J. HobBS AND H.A. Mooney. 2001. Viewing invasive species removal in a whole-ecosystem context. Trends in Ecology \& Evolution 16(8):454-459.

ZijLstra, J.S., P.A. MAdern AND L.W. van den Hoek Ostende. 2010. New genus and two new species of Pleistocene oryzomyines (Cricetidae: Sigmodontinae) from Bonaire, Netherlands Antilles. Journal of Mammalogy 91(4): 860-873. 